\title{
XXXVII. Method of avoiding certain sources of inaccuracy in the use of Kater's Horizontal floating collimator
}

\section{J. Nixon Esq.}

To cite this article: J. Nixon Esq. (1828) XXXVII. Method of avoiding certain sources of inaccuracy in the use of Kater's Horizontal floating collimator, Philosophical Magazine Series 2, 4:21, 218-219, DOI: $10.1080 / 14786442808674779$

To link to this article: http://dx.doi.org/10.1080/14786442808674779

曲 Published online: 10 Jul 2009.

Submit your article to this journal $₫$

Џ Article views: 1

Q View related articles $₫$ 


\section{Mr. Nixon on Kater's Horizontal Floating Collimator.}

Minute quantities of foreign liquids soluble in water likewise disposed the saline solution to immediate crystallization; as might be expected, and none with greater effect than alcohol. It is known that alcohol can precipitate sulphate of soda from its aqueous solutions. The soluble gases I suppose to possess a similar property.

These facts appear to warrant the conclusion, that air determines the crystallization of supersaturated saline solutions, by dissolving in the water, and thereby giving a shock to the feeble power by which the excess of salt is held in solution.

*** Since the foregoing observations were printed, the author has perceived that M. Gay-Lussac, in his paper on crystallization, (Ann. de Chim. tom. Ixxxvii.) had distinctly thrown out the same theory as a conjecture, although the circumstance is not noticed by any systematic chemical writer. But as M. Gay-Lussac brings forward no experimental illustration of the theory, and indeed adduces one experiment as unfavourable to it, the experimental confirmation of the theory is novel, and was certainly required.

XXXVII. Method of avoiding certain sources of inaccuracy in the use of Kater's Horizontal Floating Collimator. By J. Nixon, Esq.

To the Editors of the Philosophical Magazine and Annals.

Gentlemen,

$\mathrm{N}$ making use of the horizontal floating collimator of Capt. 1 Kater, in order to determine the error of collimation of the telescope of a mural circle, it is necessary to place the collimator first to the north and afterwards to the south of the circle. In addition to the consequent probable source of error, as pointed out by Capt. Kater, may we not enumerate the following?

1. In passing from the north, through the zenith to the south, the telescope describes an arc, which, from its magnitude, may give rise to a sensible error in the graduation. 2. The telescope, unless quite uniform in its parts, may have its flexure varied in consequence of being inverted in position; in which event, the error of collimation will not be the same with the telescope pointed to the north as when directed towards the south. 3. When the north and south sides of the observatory are not uniform in temperature, is it not possible that the difference may vitiate the observations?

All these sources of inaccuracy and doubt may be avoided, and the observations completed with the telescope of the cir- 
cle in one direction, by the addition of a telescope fixed on a support at such a distance from the circle that the collimator may be conveniently placed between, and in a line with, the two telescopes. To find the error of collimation with the telescope of the circle directed towards the north, proceed as follows:

1. The line of collimation of the telescope of the collimator being very nearly horizontal, place the instrument, with its telescope looking to the south, to the north of the mural circle. 2. Make the line of collimation of the telescope of the circle, (pointing northwards,) parallel to that of the telescope of the collimator, and read off the (minute) angle of elevation or depression, 3. Turn the collimator half round in azimuth, when its telescope (pointing northwards) should be in a line with the fixed telescope placed to the north of the collimator. Make the line of collimation of the fixed telescope, pointing southwards, parallel to that of the telescope of the collimator. 4. Remove the collimator, and measure by the micrometer of the fixed telescope the vertical angle formed by the intersection of its line of collimation by that of the telescope of the circle; half of which angle is the correct horizontal inclination of the line of collimation of the telescope of the circle*.

Having thus determined the northern error of collimation, we may subsequently ascertain; after the same method, the southern one; and on comparing these errors with that given by the vertical collimator with the telescope pointed towards the zenith, we obtain the horizontal flexure of the telescope for both directions. I am, Gentlemen, yours, \&c.

Leeds, Aug. 2, 1828.

JoHN Nixon.

XXXVIII. Description of a new Kind of Pear-Encrinite found in England. By John EDw. Gray, Esq.F.G.S. \&c.†

Encrinites (Apiocrinites) Prattir, n.

Specific Character :-COLUMN formed of round joints adhering by radiating surfaces.? of which the 4 or 5 top ones gradually enlarge at the apex, and sustain the pelvis, \&c.

Icon. n. Inhab. Lias, summit of Lansdown, near Bath. J. S. Pratt, Esq. Mus. Brit.

This species appears to be intermediate between $A$. rotundus and A. ellipticus of Miller, and for the sake of comparison I have given the specific character after his method.

* This angle will be an elevation, or a depression, according as the line of collimation of the fixed telescope points above, or below that of the telescope of the circle. t Communicated by the Author. 